\title{
Optimization of the Blanching of Potato (Solanum Tuberosum L) Slices by Response Surface Methodology: Effect on the Vitamin C Content and Drying Kinetics
}

\author{
Ambe Desmond, Lobe Elias, Bup Nde Divine* \\ Department of Food and Bio-resource Technology, College of Technology, University of Bamenda, Bamenda, Cameroon \\ E-mail: bupdiv@yahoo.fr
}

\begin{abstract}
Potatoes (S. tuberosum L) is one of the most important tuber crops in the world. However, its high moisture content and inadequate storage and processing techniques have a negative influence on its quality and availability throughout the year. This work was carried out to optimize the blanching behavior and drying kinetics of potato slices. Fresh potato slices $\left(5,10\right.$ and $15 \mathrm{~mm}$ ) were blanched at 70,80 and $90^{\circ} \mathrm{C}$ for 1,3 and 5 min following a $3^{\mathrm{k}}$ level full factorial design. The loss in Vitamin $\mathrm{C}$ was used as a quality marker for the optimization process. The influence of blanching on the drying behavior of potato slices was carried out at 50,60 and $70^{\circ} \mathrm{C}$. Results showed that blanching parameters had a significant $(\mathrm{P}<0.05)$ effect on vitamin $\mathrm{C}$ loss. Optimum blanching conditions were blanching temperature of $80^{\circ} \mathrm{C}$, blanching time of $3 \mathrm{~min}$ and a slice thickness of $10 \mathrm{~mm}$ which gave an average loss in Vitamin $\mathrm{C}$ of about 2.6\%. Drying data were successfully fitted to three different thin layer drying models. The use of blanching as a pretreatment before the drying of potato is recommended because it reduces the drying time by $30 \%$.
\end{abstract}

Keywords: potato, blanching, optimization, Vitamin C, drying kinetics

\section{Introduction}

Irish potato (Solanum tuberosum L.) is the fourth most important staple food crop in the world after wheat, rice, and maize ${ }^{[1]}$. Potato is appreciated for its high quality proteins, essential vitamins, minerals, very low fat content and medicinal properties ${ }^{[2]}$. With the increasing cost of wheat flour, the principal ingredient in some bakery and confectionary products, there is need to look for alternative sources of flours that can partially or fully replace wheat flour in bakery and confectionary products. One possible source of this is flour processed from potato because: firstly, potato is abundant; about 459 million tons of potatoes were produced in 2018 worldwide ${ }^{[3]}$. Secondly with improved research techniques, several high yielding varieties can now be produced which are resistant to pests and diseases ${ }^{[4-5]}$. Thirdly different varieties of potatoes can have important nutrients including carotenoids, flavonoids and phenolic compounds ${ }^{[6]}$. However, inadequate attention to appropriate postharvest handling, storage and processing techniques to make potatoes available throughout the year is a drawback to further development of the crop. This is because potatoes are not only seasonal but have high moisture content of about $88 \%$ which make them highly perishable ${ }^{[7]}$. As a result, they deteriorate very fast few months after harvest, losing almost all their required quality attributes. One way of prolonging the shelf of potato is by the production of potato flour that can be incorporated into formulations for bakery and confectionery products. Blanching and drying are some of the major steps involved in the processing of potatoes into flour. Blanching is a pre-processing step that limits product degradation during subsequent processing thereby enhancing quality. Drying is an important technique that reduces the moisture content of a product rendering it less susceptible to attack by micro-organisms and thereby prolonging its shelf-life. Drying offers a highly effective and practical means of preservation to reduce postharvest losses and offset the shortages in supply from causes such as mechanical damage, decay, premature and unseasonable germination of the produce. Knowledge of the drying kinetics and its modelling is important for dryer design and construction as well as in the optimization of the drying process ${ }^{[8]}$. Previous works on the blanching and/or drying of potato slices ${ }^{[9-12]}$ have not addressed the optimum conditions that minimize loss of Vitamin $\mathrm{C}$ as well as its effects on the drying behavior of potato slices. Vitamin $\mathrm{C}$ has been used as a marker to evaluate the influence of different process techniques on the quality of a food product ${ }^{[13-14]}$. This work evaluates the influence of blanching on Vitamin C loss and on the drying kinetics of fresh

Copyright (C2020 Ambe Desmond et al.

DOI: https://doi.org/10.37256/sce.11202082.17-32

This is an open-access article distributed under a CC BY license

(Creative Commons Attribution 4.0 International License)

https://creativecommons.org/licenses/by/4.0/ 
potato in the form of slices to a suitable moisture content that can be further processed into other stable products such as flour and flakes.

\section{Material and methods}

A local variety (Superior) of fresh potato tubers were purchased from a local market in Bamenda Cameroon $\left(5.96^{\circ} \mathrm{N}\right.$ and $10.16^{\circ} \mathrm{E}$ ). The work was carried out in two phases; optimization of the blanching process followed by the drying behavior of the slices.

\subsection{Blanching process}

Investigations were carried out to determine the optimum blanching conditions that minimize loss of Vitamin $\mathrm{C}$ and to determine the effect of blanching on the drying process. Three independent variables; slice thickness $\left(X_{I}\right)$, blanching temperature $\left(X_{2}\right)$ and blanching time $\left(X_{3}\right)$ were used in the study. A full factorial 3 level $\left(3^{\mathrm{k}}\right)$ design (FFD) with $\mathrm{k}=3$ factors was used in the study. $27\left(3^{\mathrm{k}}\right)$ experiments were carried out in triplicates to evaluate the effect of blanching on the loss of vitamin C. A 3 level FFD permits to effectively study the influence of the independent parameters as well as the interaction of the parameters on the blanching process. The coded values of the three independent variables and the experimental design are presented in Tables 1 and 3 respectively.

\begin{tabular}{cccc}
\multicolumn{4}{c}{ Table 1. Coded and real levels for the FFD } \\
\hline Variables & \multicolumn{3}{c}{ Level } \\
\hline Coded & -1 & 0 & 1 \\
$X_{I}(\mathrm{~mm})$ & 5 & 10 & 15 \\
$X_{2}\left({ }^{\circ} \mathrm{C}\right)$ & 70 & 80 & 90 \\
$X_{3}(\mathrm{~min})$ & 1 & 3 & 5 \\
\hline
\end{tabular}

\subsubsection{Experimental procedure of the blanching process}

Mature and undamaged potato tubers were peeled and cut along the main axis of the whole tuber into slices with thicknesses of 5, 10 and $15 \mathrm{~mm}$, using a sharp stainless steel knife. A Vernier caliper (GILSON TOOLS, Japan) was used to measure the thickness of slices. The other dimensions (length and width) were not kept constant for all the samples. Blanching of the potato slices was carried out in a digital water bath (SWB6D Stuart, UK). $500 \mathrm{ml}$ of distilled water was placed in a beaker and the beaker immersed in the water bath. When the desired temperature was attained, $50 \mathrm{~g}$ of the sample were then immersed into the water and blanched for the required time as shown on table 3. After blanching, the water left (stock) was titrated against a $0.01 \mathrm{M}$ iodine solution to determine the quantity of Vitamin $\mathrm{C}$ lost in the blanching process.

\subsubsection{Analysis of the blanching results}

To evaluate the influence of the parameters on the blanching process, the experiments were transformed into a mathematical equation of the form

$$
Y=\beta_{0}+\beta_{1} x_{1}+\beta_{2} x_{2}+\beta_{3} x_{3}+\beta_{11} x_{1}^{2}+\beta_{22} x_{2}^{2}+\beta_{33} x_{3}^{2}+\beta_{12} x_{1} x_{2}+\beta_{13} x_{1} x_{3}+\beta_{23} x_{2} x_{3}
$$

Where, $\beta_{0}$ is a constant; $\beta_{1}, \beta_{2}$ and $\beta_{3}$ are the linear; $\beta_{11}, \beta_{22}$ and $\beta_{33}$ are the quadratic; $\beta_{12}, \beta_{13}$ and $\beta_{23}$ are the interaction regression coefficients respectively. $x_{1}, x_{2}$ and $x_{3}$ are the coded independent variables of slice thickness, blanching temperature and blanching time.

Model parameters, ANOVA table, optimum points and $\mathrm{R}^{2}$ values were generated on JMP Pro 13; a specialized software for experimental design analysis.

The determined optimum points were then used to blanch potato slices before drying.

\subsection{Drying experiments}

\subsubsection{Measurement of drying kinetics}

All drying experiments were carried out in an electrically heated conventional laboratory oven (DHG-9101-1SA, Gen Lab, China) under natural convection. The desired temperature was set and the oven was allowed to achieve steadystate conditions. A thin layer of potato slices weighing about $25 \mathrm{~g}$ was distributed uniformly on a sheet of baking paper and the sample was then placed onto the oven shelf. Moisture loss was recorded periodically using a high precision balance 
(Model KD-CN) as a function of drying time. For this purpose, the drying samples were withdrawn from the oven at 30 minute intervals throughout the drying process, rapidly weighed and replaced in the oven. The weighing of the product was performed in approximately 40 seconds and did not significantly change the steady-state drying conditions ${ }^{[15]}$. Drying was done in triplicates.

\subsubsection{Moisture content determination}

Five grams of potato slices were weighed and transferred to a previously washed, dried and weighed crucible. The crucible containing the sample was placed in a laboratory dry oven (LABTECH, India) at $105{ }^{\circ} \mathrm{C}$ for twenty-four (24) hours. \% moisture content was obtained by difference.

\subsubsection{Evaluation of drying rate}

Drying rate was determined from the drying data using equation 2.

$$
\frac{d M}{d t}=\frac{M_{i}-M_{i+1}}{t_{i}-t_{i+1}}
$$

Where $d M / d \mathrm{t}=$ drying rate, recent moisture loss per $\min (\% / \mathrm{min}), M_{\mathrm{i}}=$ moisture content $(\% \mathrm{db})$ of sample at time $\mathrm{t}_{\mathrm{i}}$, $M_{\mathrm{i}+1}=$ moisture content $(\% \mathrm{db})$ of sample at time $\mathrm{t}_{\mathrm{i}+1}$

\subsubsection{Modelling of the drying kinetics}

Three models frequently used in the literature to describe the drying kinetics of some foods and vegetables were used in this work (Table 2).

Table 2. List of different drying models used

\begin{tabular}{cccc}
\hline No. & Model & Model equation & Reference \\
\hline 1 & Newton & MR=exp $(-\mathrm{kt})$ & {$[16]$} \\
2 & Henderson and Pabis & $\mathrm{MR}=\mathrm{a} \exp (-\mathrm{kt})$ & {$[17]$} \\
3 & Page & $\mathrm{MR}=\exp \left(-\mathrm{kt}^{\mathrm{n}}\right)$ & {$[18]$} \\
\hline
\end{tabular}

Where, $K$ is drying constant $\left(\mathrm{s}^{-1}\right)$ a, $c$, and $n$ are model parameters. Moisture ratio $\left(M_{R}\right)$ at time $t$ was calculated from the equation

$$
M_{R}=\frac{M_{t}-M_{e}}{M_{0}-M_{e}}
$$

Where $\mathrm{M}_{\mathrm{t}}=$ Moisture content at time, $\mathrm{t}(\% \mathrm{db}), \mathrm{M}_{\mathrm{e}}=$ Equilibrium or final moisture content $(\%, \mathrm{db}), \mathrm{M}_{\mathrm{o}}=\mathrm{Initial}$ moisture content $(\% \mathrm{db})$. In order to evaluate the constants $k, n$ and $a$ in the models, the respective model equations were expressed in their linear forms.

The suitability of the tested models in describing the blanching and drying processes of potato slices was determined the coefficient of variation $\left(\mathrm{R}^{2}\right)$ and a plot of the measured versus predicted data and the Average Standard Error of Deviation (SED) between experimental and predicted results (SED). $\mathrm{R}^{2}$ value was obtained directly from linear regression analysis while SED was obtained from equation 4.

$$
S E D=\frac{\sum 100 *\left|\frac{Y_{\text {exp }}-Y_{\text {pre }}}{Y_{\text {exp }}}\right|}{n}
$$

$\mathrm{n}$ is the number of experiments, $Y_{\exp }$ and $Y_{\text {pre }}$ denoted measured and predicted values respectively. A model was considered valid if $\mathrm{R}^{2}>70 \%$ and/or $\mathrm{SED}<10 \%{ }^{[19-20]}$.

\section{Results and disscussion}

\subsection{Blanching of raw potato slices}


Experimental and predicted values of loss in Vitamin $\mathrm{C}$ are presented in Table 3. Table 4 shows the ANOVA table for the blanching process. The F-value is less than 0.05 indicating that the factors studied hand a significant effect on the blanching process. Recorded values for the model constants are presented in Table 5.

Table 3. Coded and real values and the experimental and predicted loss in Vitamin C during blanching

\begin{tabular}{|c|c|c|c|c|c|c|c|c|c|}
\hline \multirow{2}{*}{ Experiment No. } & \multicolumn{3}{|c|}{ Coded Values } & \multicolumn{3}{|c|}{ Real Values } & \multicolumn{3}{|c|}{ Response } \\
\hline & $x_{1}$ & $x_{2}$ & $x_{3}$ & $X_{I}$ & $X_{2}$ & $X_{3}$ & $\mathbf{V}_{\text {Cexp }}$ & $\mathbf{V}_{\text {Cpre }}$ & SED \\
\hline 1 & -1 & -1 & -1 & 5 & 70 & 1 & 2.05 & 1.97 & 3.52 \\
\hline 2 & -1 & -1 & 0 & 5 & 70 & 3 & 2.22 & 2.29 & 3.16 \\
\hline 3 & -1 & -1 & 1 & 5 & 70 & 5 & 2.53 & 2.60 & 2.76 \\
\hline 4 & -1 & 0 & -1 & 5 & 80 & 1 & 2.22 & 2.39 & 8.06 \\
\hline 5 & -1 & 0 & 0 & 5 & 80 & 3 & 2.79 & 2.78 & 0.41 \\
\hline 6 & -1 & 0 & 1 & 5 & 80 & 5 & 3.26 & 3.16 & 3.15 \\
\hline 7 & -1 & 1 & -1 & 5 & 90 & 1 & 2.86 & 2.81 & 1.63 \\
\hline 8 & -1 & 1 & 0 & 5 & 90 & 3 & 3.31 & 3.27 & 1.30 \\
\hline 9 & -1 & 1 & 1 & 5 & 90 & 5 & 3.71 & 3.72 & 0.14 \\
\hline 10 & 0 & -1 & -1 & 10 & 70 & 1 & 1.94 & 1.84 & 5.11 \\
\hline 11 & 0 & -1 & 0 & 10 & 70 & 3 & 2.16 & 2.15 & 0.47 \\
\hline 12 & 0 & -1 & 1 & 10 & 70 & 5 & 2.42 & 2.47 & 1.95 \\
\hline 13 & 0 & 0 & -1 & 10 & 80 & 1 & 2.13 & 2.26 & 6.19 \\
\hline 14 & 0 & 0 & 0 & 10 & 80 & 3 & 2.65 & 2.64 & 0.07 \\
\hline 15 & 0 & 0 & 1 & 10 & 80 & 5 & 3.13 & 3.03 & 3.21 \\
\hline 16 & 0 & 1 & -1 & 10 & 90 & 1 & 2.64 & 2.68 & 1.73 \\
\hline 17 & 0 & 1 & 0 & 10 & 90 & 3 & 3.19 & 3.13 & 1.88 \\
\hline 18 & 0 & 1 & 1 & 10 & 90 & 5 & 3.52 & 3.59 & 2.00 \\
\hline 19 & 1 & -1 & -1 & 15 & 70 & 1 & 1.77 & 1.71 & 3.02 \\
\hline 20 & 1 & -1 & 0 & 15 & 70 & 3 & 1.95 & 2.02 & 3.82 \\
\hline 21 & 1 & -1 & 1 & 15 & 70 & 5 & 2.33 & 2.33 & 0.37 \\
\hline 22 & 1 & 0 & -1 & 15 & 80 & 1 & 2.05 & 2.13 & 4.13 \\
\hline 23 & 1 & 0 & 0 & 15 & 80 & 3 & 2.54 & 2.51 & 1.06 \\
\hline 24 & 1 & 0 & 1 & 15 & 80 & 5 & 3.00 & 2.89 & 3.42 \\
\hline 25 & 1 & 1 & -1 & 15 & 90 & 1 & 2.66 & 2.55 & 4.25 \\
\hline 26 & 1 & 1 & 0 & 15 & 90 & 3 & 2.99 & 3.00 & 0.54 \\
\hline 27 & 1 & 1 & 1 & 15 & 90 & 5 & 3.29 & 3.45 & 4.87 \\
\hline \multicolumn{9}{|c|}{ Average SED (\%) } & 2.67 \\
\hline \multicolumn{9}{|c|}{$\mathbf{R}^{2}$} & 0.978 \\
\hline
\end{tabular}

$x_{1}, x_{2}, x_{3}$, and $X_{1}, X_{2}, X_{3}$ are coded and real values of slice thickness, blanching temperature and blanching time respectively. $\mathrm{R}^{2}$ is the coefficient of variation, SED is the Average Standard Error of Deviation

Table 4. ANOVA table for the blanching process

\begin{tabular}{cccccc}
\hline & $d f$ & $S S$ & $M S$ & $F$ & Significance $F$ \\
\hline Regression & 9 & 7.31 & 0.81 & 81.59 & 0.00 \\
Residual & 17 & 0.17 & 0.01 & & \\
Total & 26 & 7.48 & & & \\
\hline
\end{tabular}


Table 5. Model constants and their $P$ values for the selected equation

\begin{tabular}{ccc}
\hline Constant & Coefficients $(\beta i)$ & $P$-value \\
\hline Intercept & 2.6443 & 0.00 \\
$x_{1}$ & -0.1310 & 0.00 \\
$x_{2}$ & 0.4899 & 0.00 \\
$x_{3}$ & 0.3813 & 0.00 \\
$x_{1} x_{1}$ & -0.0027 & 0.95 \\
$x_{2} x_{2}$ & 0.0016 & 0.97 \\
$x_{3} x_{3}$ & -0.0054 & 0.90 \\
$x_{1} x_{2}$ & -0.0155 & 0.60 \\
$x_{1} x_{3}$ & -0.0197 & 0.50 \\
$x_{2} x_{3}$ & 0.0703 & 0.03 \\
\hline
\end{tabular}

$x_{1}, x_{2}, x_{3}$ are coded values of slice thickness, blanching temperature and blanching time respectively

A high coefficient of determination, $\left(\mathrm{R}^{2}=0.978\right)$, indicated that $97.8 \%$ of the variability in the response could be explained by the model. The standard error of deviation, SED of $2.67 \%$ was also very satisfactory thereby confirming the validity of the model. The fitness of this model was further validated by plotting the experimental values of vitamin $C$ loss against the predicted values as shown on Figure 1. The distribution of approximately equal number of points close and on both sides of the diagonal represents equality between the experimental and predicted values and therefore illustrates the suitability of the quadratic model for describing the blanching behavior of potato slices.

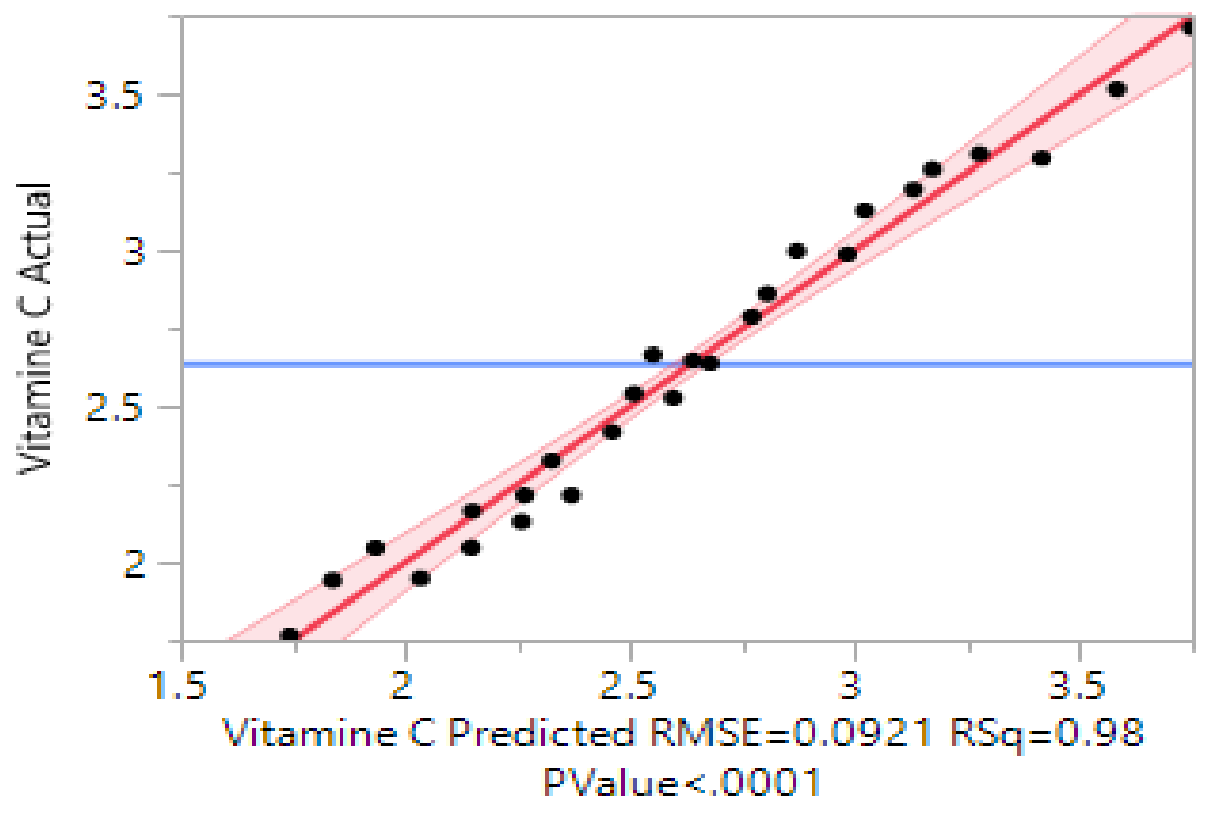

Figure 1. A plot of predicted versus experimental values of vitamin C loss

The $P$ values were used as a tool to check the significance of each coefficient, which also indicated the interaction strength of each parameter. The smaller the $P$ values are, the higher the significance of the corresponding coefficient. The corresponding $P$ values suggest that among the test variables used in this study, the square terms of $X_{1}, X_{2}$ and $X_{3}$ were highly insignificant; each of them exerting less than $0.01 \%$ influence on the response and could be neglected.

Equation (1) can therefore be written as

$$
Y=2.644258-0.13103 x_{1}+0.489907 x_{2}+0.381296 x_{3}-0.01549 x_{1} x_{2}-0.01965 x_{1} x_{3}+0.070325 x_{2} x_{3}
$$


Table 6. Contribution of each factor to loss in vitamin C

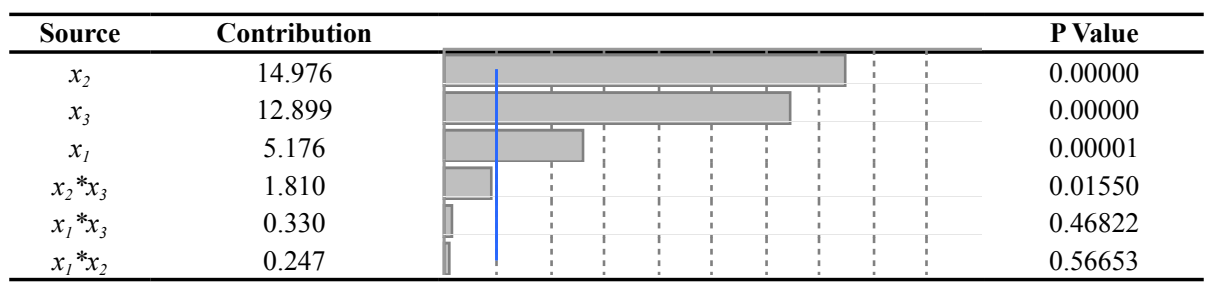

$x_{1}, x_{2}, x_{3}$ are coded values of slice thickness, blanching temperature and blanching time respectively

The higher the contribution of each factor, the higher its effect on the loss of vitamin $\mathrm{C}$. Table 6 indicates that the greatest loss in Vitamin $\mathrm{C}$ was provoked by $\mathrm{X}_{2}$ (Temperature) followed by $\mathrm{X}_{3}$ (blanching time). The validated equation was used to plot surface response curves to analyze the interaction effects of the variables on loss in Vitamin $\mathrm{C}$ as explained later.

\subsubsection{Effect of blanching temperature on vitamin C loss}

Results obtained showed that blanching temperature and time had a significant influence $(\mathrm{P}<0.05)$ on the vitamin $\mathrm{C}$ loss for all the slice thicknesses (Figure 2). Irrespective of the particle size, blanching losses were lowest at $70^{\circ} \mathrm{C}$ and increased significantly at 80 and $90^{\circ} \mathrm{C}$. As expected, blanching losses increased significantly with blanching time. These observations might be due to the thermal sensitivity of vitamin $\mathrm{C}$ and its high solubility in water. High temperatures and prolonged heating times provoke the degradation of vitamin $\mathrm{C}$ and its subsequent leaching into the hot water. Increase in blanching temperature also increases the permeability or disruption of cell membranes leading to increase diffusion of vitamin $\mathrm{C}$ (ascorbic acid) into the blanching medium ${ }^{[21]}$.

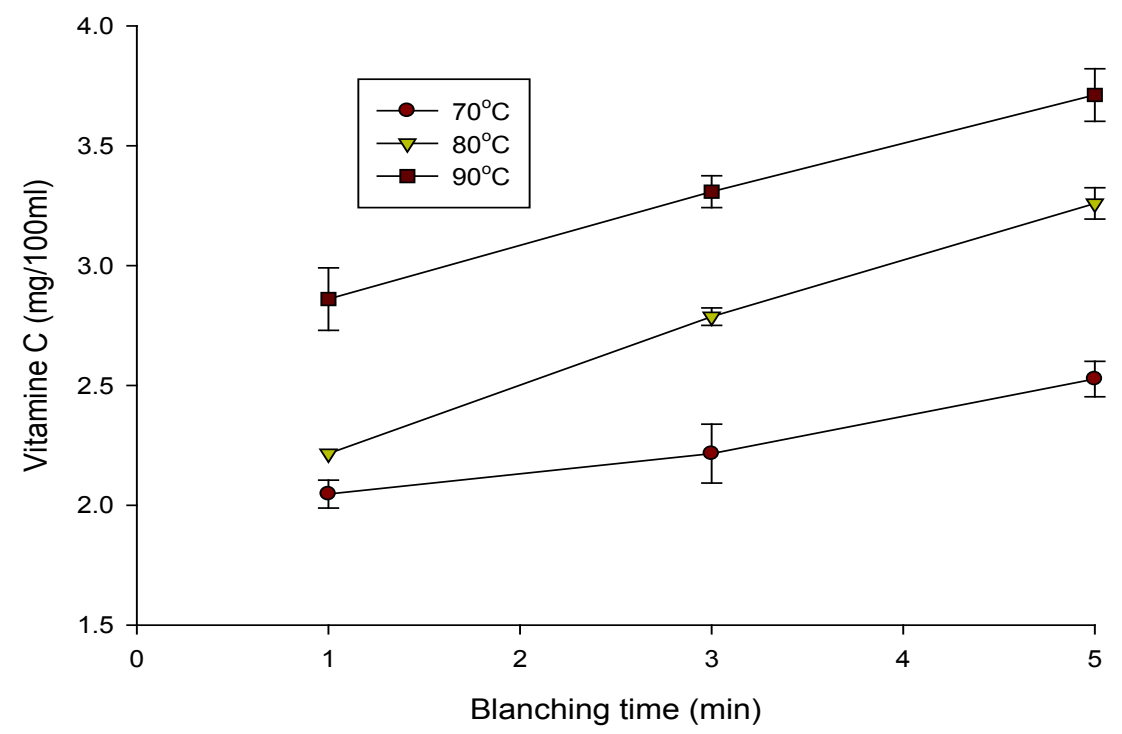

Figure 2. Influence of blanching temperature on Vitamin $\mathrm{C}$ for $5 \mathrm{~mm}$ thick potato slice (Similar trends were obtained for the 10 and $15 \mathrm{~mm}$ thick slices).

\subsubsection{Effects of slice thickness on Vitamin C loss}

Results revealed that slice thickness has a significant $(\mathrm{P}<0.05)$ influence on vitamin $\mathrm{C}$ loss during blanching. The vitamin $\mathrm{C}$ loss during blanching decreased with an increase in slice thickness at all temperatures (Figure 3 ). Highest and lowest Vitamin $\mathrm{C}$ losses were recorded with the 15 and $5 \mathrm{~mm}$ thick slices respectively. For thicker slices, there is an increased distance for water diffusion and heat penetration from the surface to the interior such that Vitamin $\mathrm{C}$ is least affected compared to the thinner slices hence the reduced leaching of Vitamin $\mathrm{C}$ into the blanching water. 


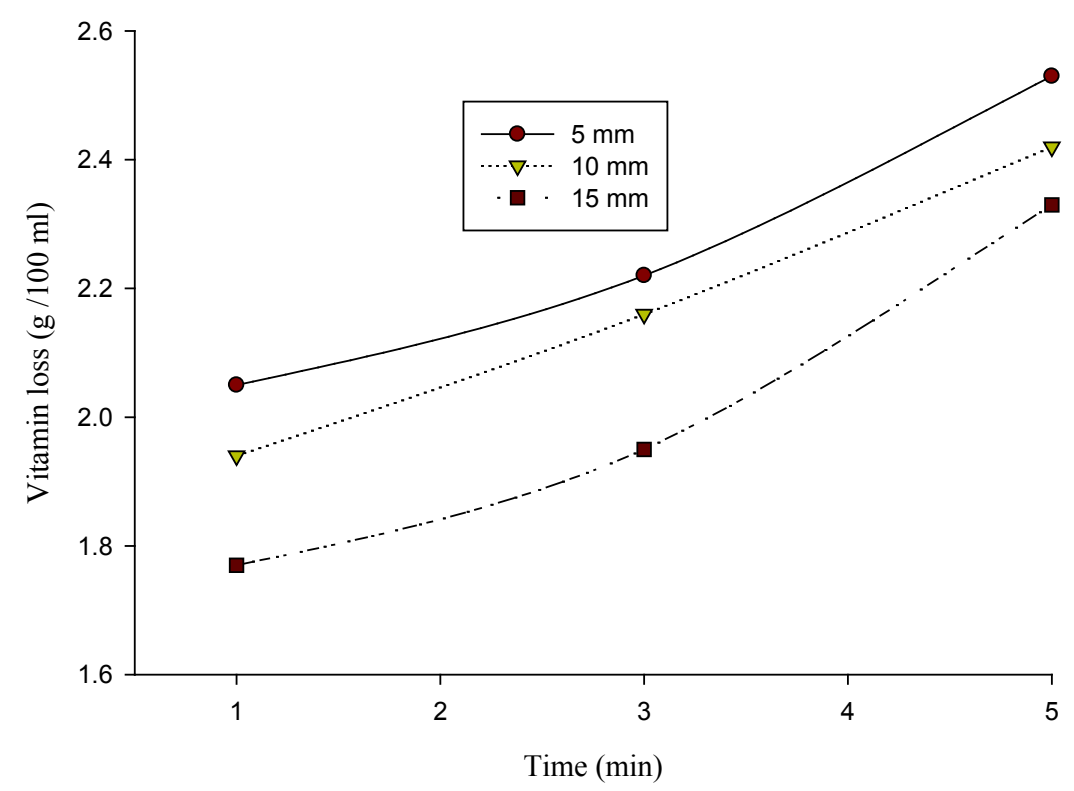

Figure 3. Influence of Slice thickness on Vitamin $\mathrm{C}$ loss as a function of blanching time at $80^{\circ} \mathrm{C}$ (Similar trends were obtained at 70 and $90^{\circ} \mathrm{C}$ )

\subsubsection{Interaction effects of process parameters on Vitamin C loss}

The combined effect of blanching temperature and time $\left(X_{2}^{*} X_{3}\right)$ at constant slice thickness is shown on Figure 4. It can be observed that both parameters have and increasing effect on the loss of vitamin $\mathrm{C}$ with losses occurring at highest heating temperature and prolonged heating. Reasons earlier adduced for increase loss in Vitamin $\mathrm{C}$ at increased temperature and prolonged heating are responsible for this. In fact, table 6 confirms that blanching temperature and time exhibited the highest significant effects on the loss of Vitamin $\mathrm{C}$ during the blanching process.

Figures 5 and 6 give the combined effect of time and thickness $\left(X_{3}^{*} X_{1}\right)$ and temperature and thickness $\left(X_{2}^{*} X_{1}\right)$ respectively on Vitamin $C$ loss. It is observed that irrespective of the blanching temperature or time, thickness had a noticeable reducing effect on the loss of Vitamin C. This is a pointer to the fact that, when possible blanching should be done with relatively thick slices to minimize Vitamin C losses.

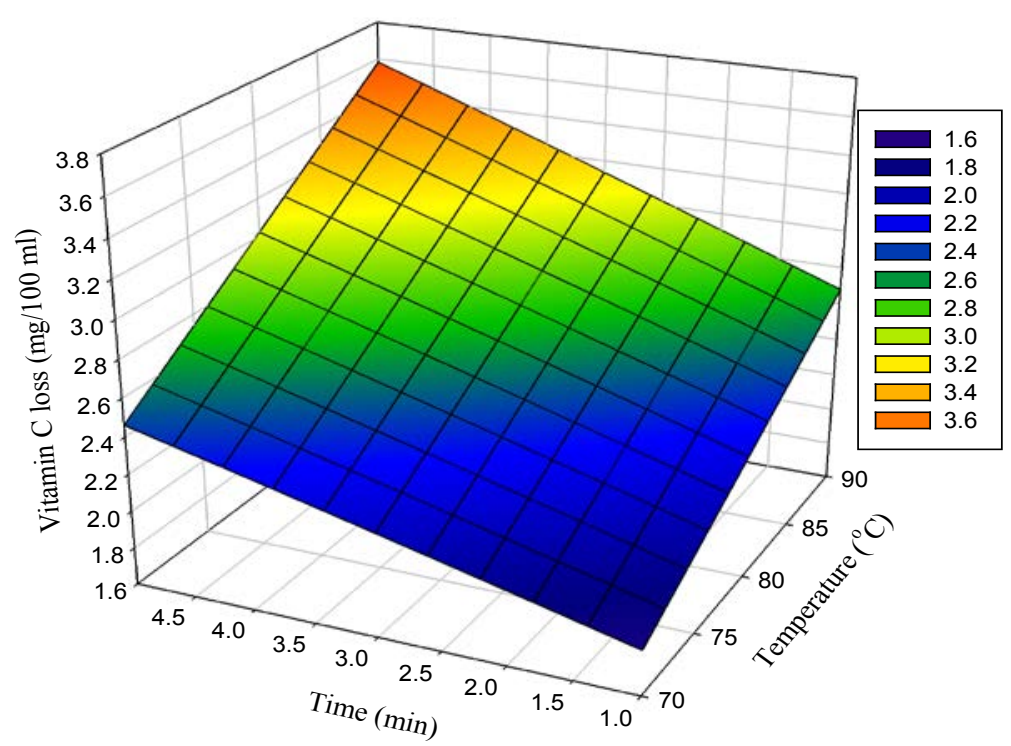

Figure 4. Interaction effect of time and temperature on vitamin $C$ loss at constant slice thickness $\left(\mathrm{X}_{1}=10 \mathrm{~mm}\right)$ 


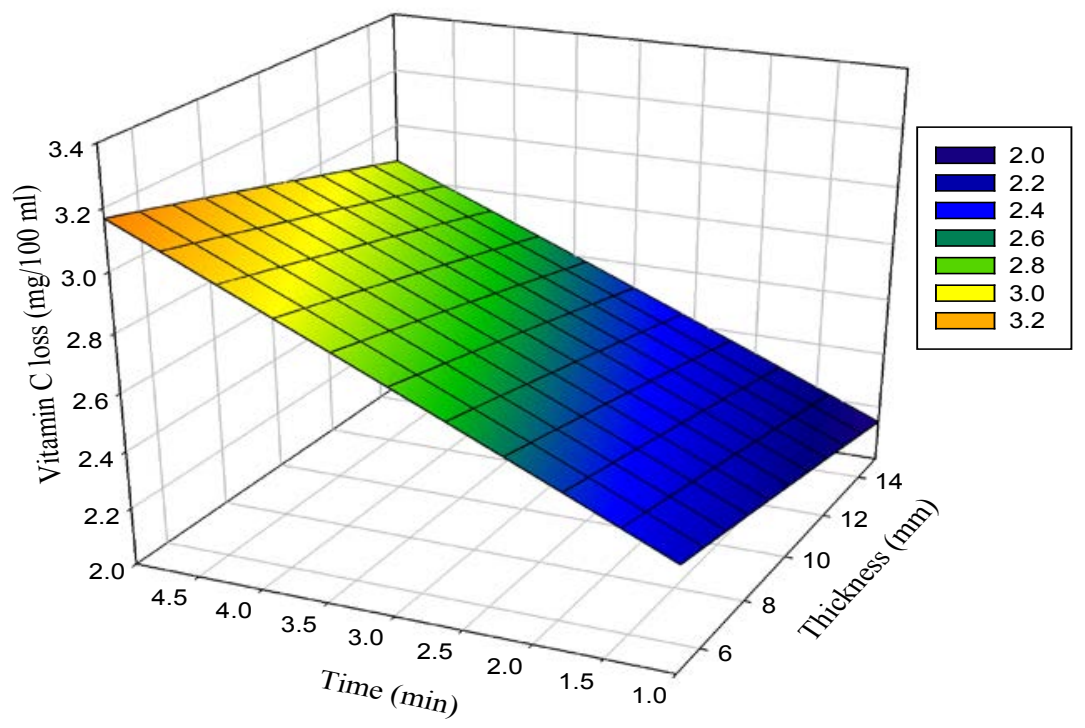

Figure 5. Interaction effect of time and thickness on vitamin $\mathrm{C}$ loss at constant temperature $\left(\mathrm{X}_{2}=80^{\circ} \mathrm{C}\right)$

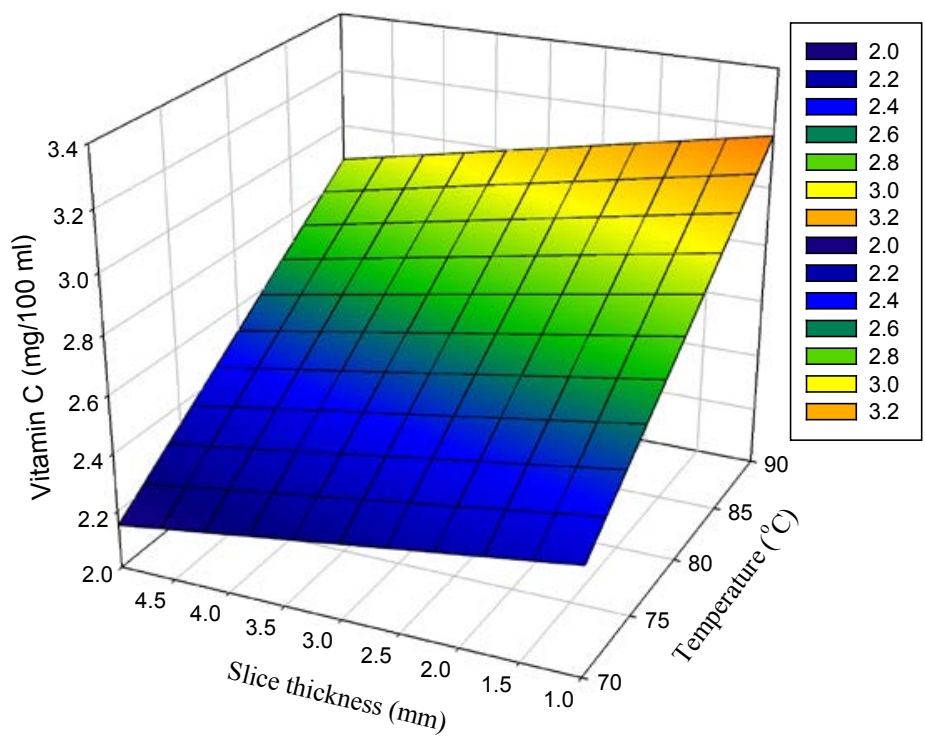

Figure 6. Interaction effect of temperature and thickness on Vitamin $C$ loss at constant time $\left(X_{3}=3\right.$ min)

Optimization of the blanching process by minimization of the loss in Vitamin C content on JMP Pro 13 software gave optimum blanching conditions for potato slices as: blanching temperature of $80^{\circ} \mathrm{C}$, for 3 minutes and at slice thickness of $10 \mathrm{~mm}$. Under these conditions Vitamin C loss was about 2.6\%. That is, under these conditions about $97 \%$ of the Vitamin $\mathrm{C}$ in potato slices is retained.

\subsection{Drying behaviour of raw potato}

\subsubsection{Effects of drying air temperature}

The effect of drying temperature $\left(50,60,70^{\circ} \mathrm{C}\right)$ on drying kinetics of potato slices is shown on Figure 7 . It can be observed that the moisture content of potato slices decreased continuously until the moisture content reached its equilibrium. At $50^{\circ} \mathrm{C}$, the moisture content for the $5 \mathrm{~mm}$-thick slice reduced from its initial value of 4.88 to $0.007 \mathrm{~g}$ water /g DM (db) in 780. Corresponding values at 60 and $70^{\circ} \mathrm{C}$ were 660 and $480 \mathrm{~min}$. That is, increasing the drying air 
temperature resulted in a decrease in drying time. Abano et al. ${ }^{[22]}$ reported a reduction in drying time for tomato slices from 1140 to $540 \mathrm{~min}$ when temperature increased from 50 to $80^{\circ} \mathrm{C}$. This might be attributed to the fact that at higher drying air temperature there is a greater moisture evaporation rate at the food/air interface due to a greater rate of heat transfer into the potato samples from the drying air. The higher moisture evaporation rate causes a higher rate of moisture to diffuse from the internal regions of the potato slices to the surface thereby increasing the drying rates and reducing drying times ${ }^{[23]}$.

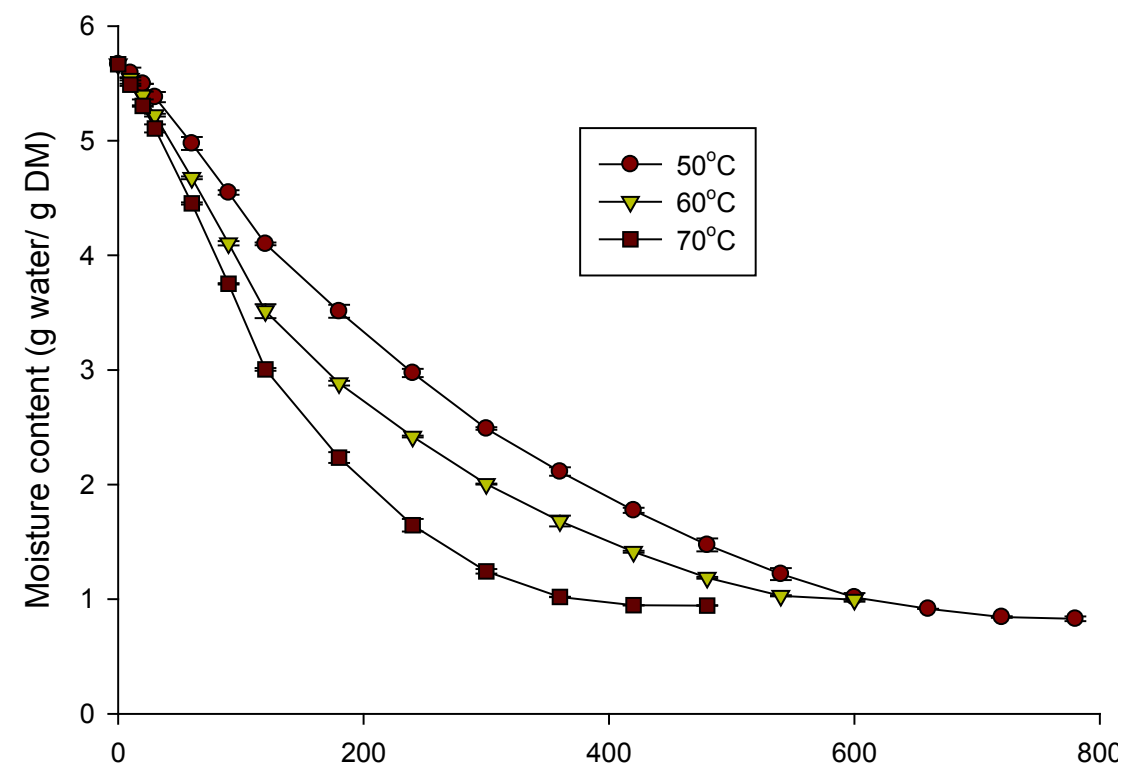

Figure 7. Drying curves of 5 mm-thick potato slices at different drying temperatures

The variation of the drying rates as a function of moisture content $(\mathrm{db})$ for the $5 \mathrm{~mm}$-thick potato slices is shown in Figure 8. It can be seen actually from Figure 8 that all the three phases of drying were observed in the drying of blanched potato slices. The first phase is the temperature attainment phase which corresponds to the heating up of the product to the experimental temperature, the second is the constant rate phase which corresponds to the removal of free water and the third is the falling rate period which corresponds to the removal of bound water. A typical pattern in the drying curves of agricultural products is that the whole drying process occurs in the falling rate period as no constant drying rate period is usually observed ${ }^{[24]}$. The observance of a constant rate period could be due to the high initial moisture content of the potato tubers. 


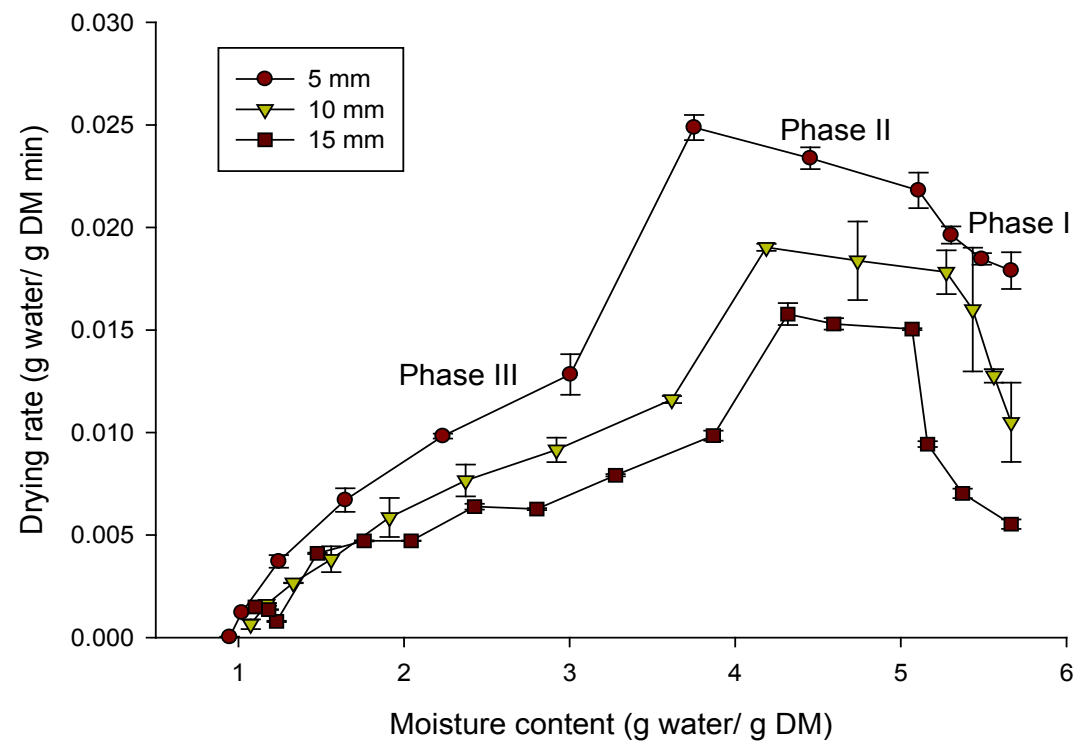

Figure 8. Drying rate curves at different temperatures for the $5 \mathbf{~ m m}$-thick potato slices

\subsubsection{Effects of slice thickness}

The effect of slice thickness $(5,10$ and $15 \mathrm{~mm})$ on the drying kinetics of potato slices dried at $70^{\circ} \mathrm{C}$ is shown on Figs. $9 \mathrm{a}$ and $\mathrm{b}$. It is immediately apparent from the respective figures that the drying time increased while drying rate decreased with increasing thickness of the samples when all other process variables remained constant.

When $5 \mathrm{~mm}$ thick potato slices were dried, the equilibrium moisture content was attained after $480 \mathrm{~min}$ at $70^{\circ} \mathrm{C}$. This moisture level was reached after 600 and $780 \mathrm{~min}$ with the 10 and $15 \mathrm{~mm}$ slice thickness respectively. The thinly sliced potato samples $(5 \mathrm{~mm})$ dried faster compared to thick slices at all the three selected temperatures due to the reduced distance the moisture travels and the increased surface area exposed for a given volume of the product. The dependence of drying rate on thickness indicates that the drying of potato slices was controlled by internal mass transfer ${ }^{[25]}$.

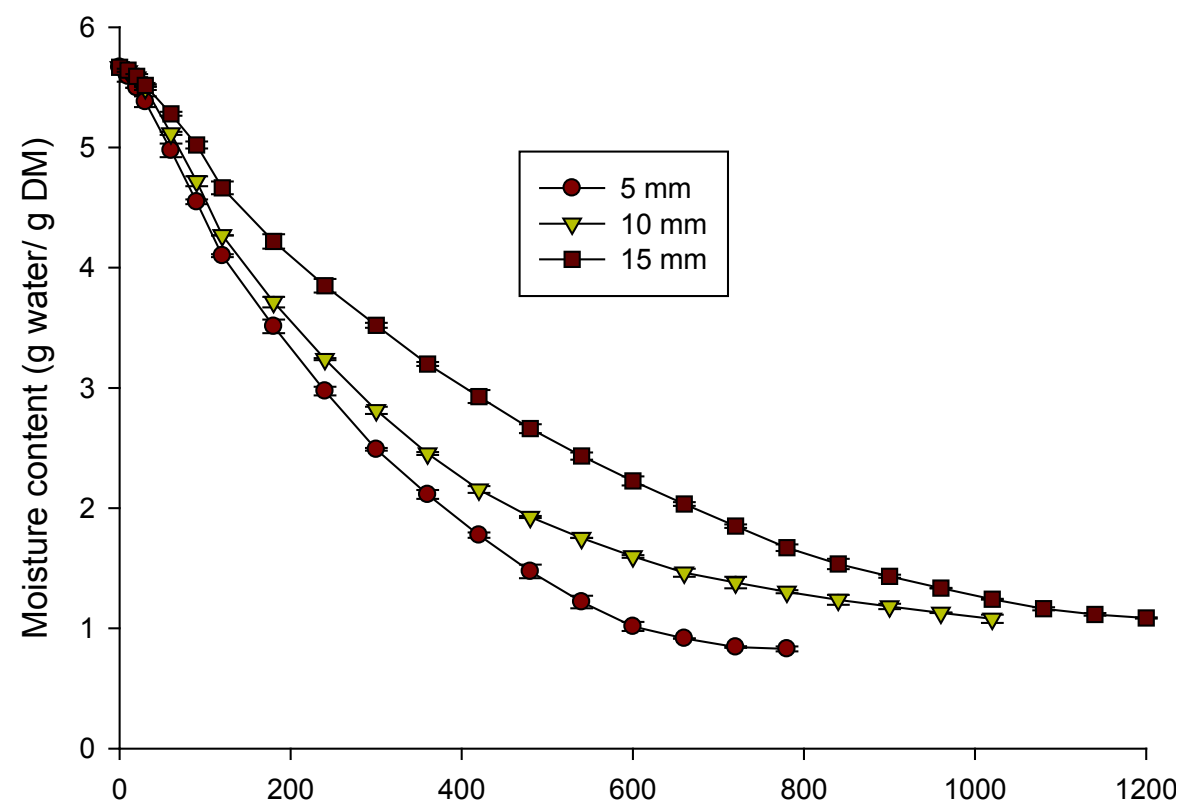

Figure 9a. Effects of thickness on the drying kinetics of potato slices at $70^{\circ} \mathrm{C}$ (similar trends were obtained at 50 and $600 \mathrm{C}$ ) 


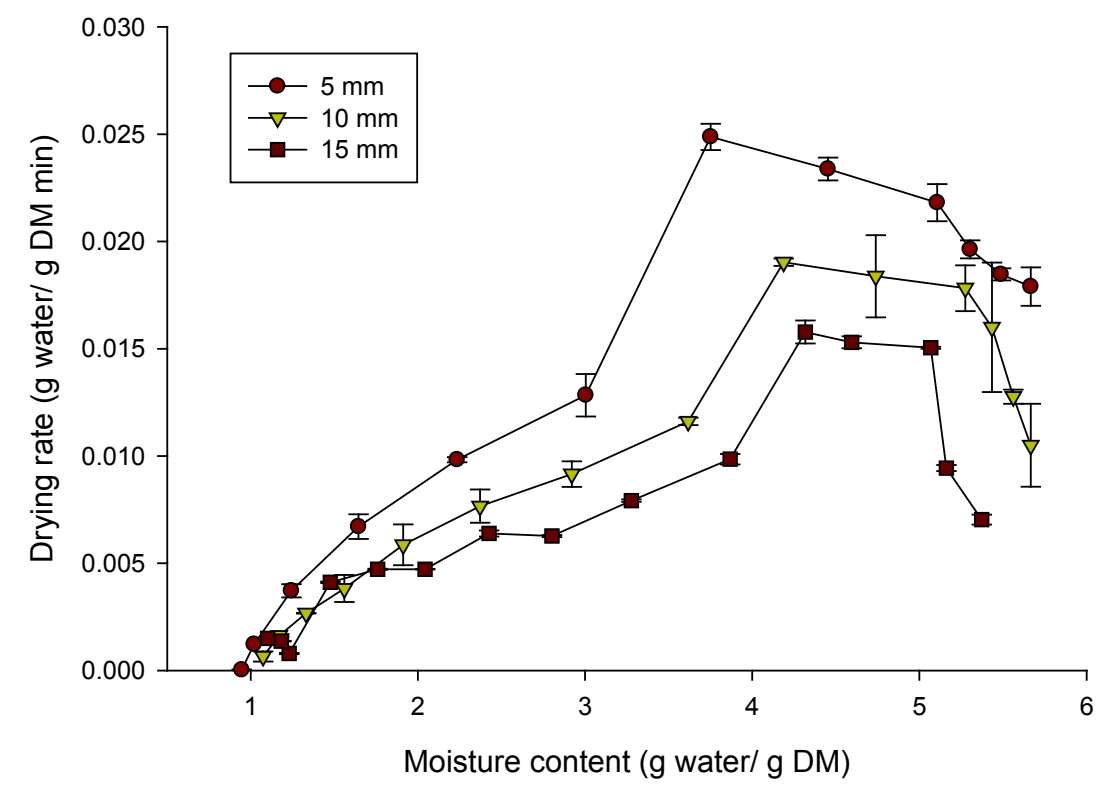

Figure 9b. Drying rate curves for different slice thicknesses at $70^{\circ} \mathrm{C}$

\subsubsection{Effect of blanching on the drying kinetics}

At $50^{\circ} \mathrm{C}$, except for the $5 \mathrm{~mm}$ thick slices (Figure 10a), it was observed that there was a significant difference $(\mathrm{P}<0.05)$ between the 10 and $15 \mathrm{~mm}$ thick blanched and the un-blanched potato slices in the rate of moisture removal.

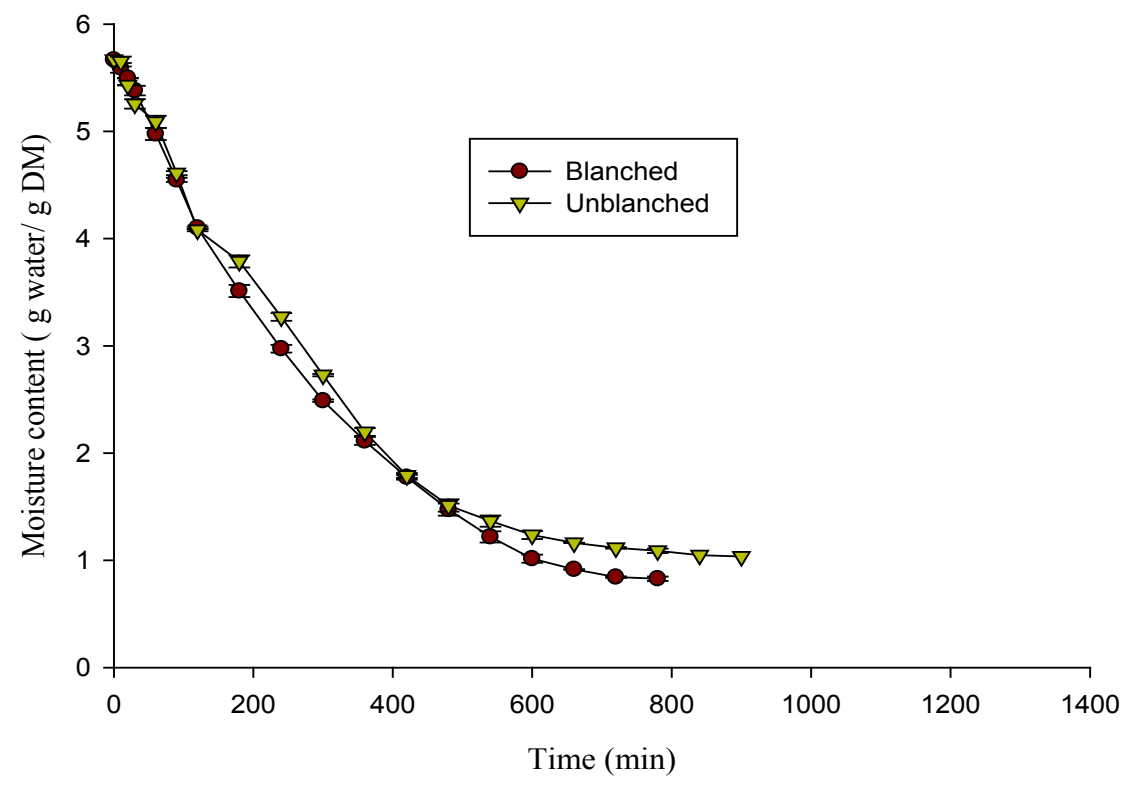

Figure 10a. Effect of blanching on the drying kinetics of $5 \mathrm{~mm}$-thick slices at $50^{\circ} \mathrm{C}$ 


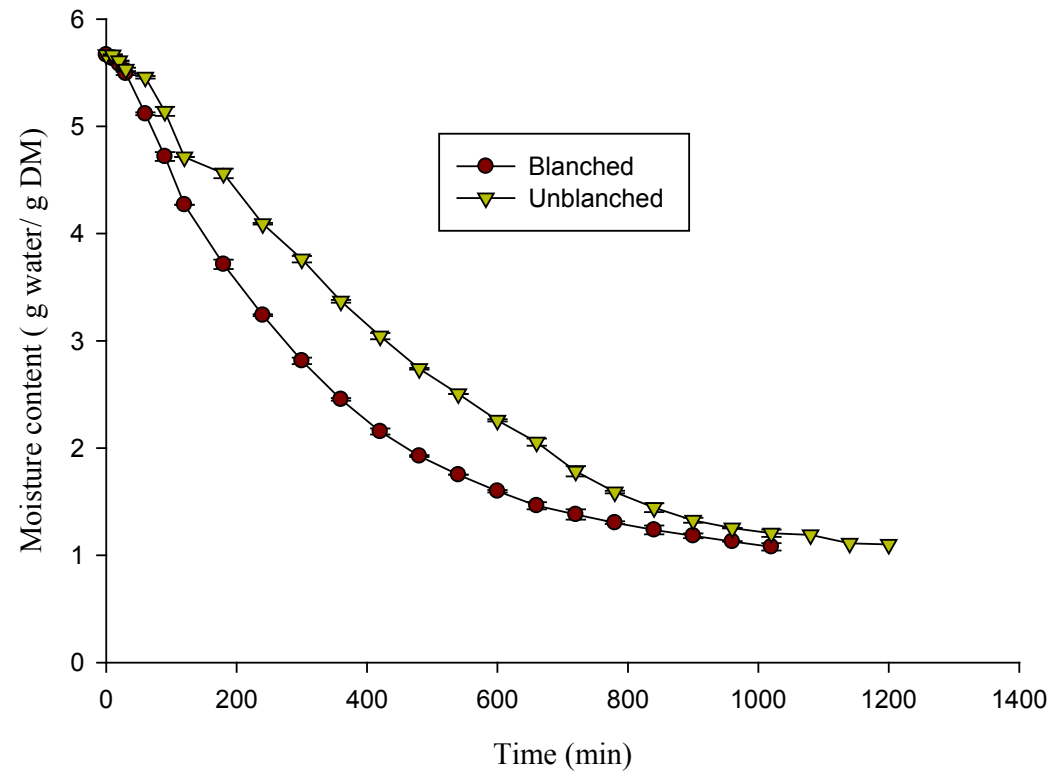

Figure 10b. Effect of blanching on the drying kinetics of $10 \mathrm{~mm}$-thick slices at $50^{\circ} \mathrm{C}$

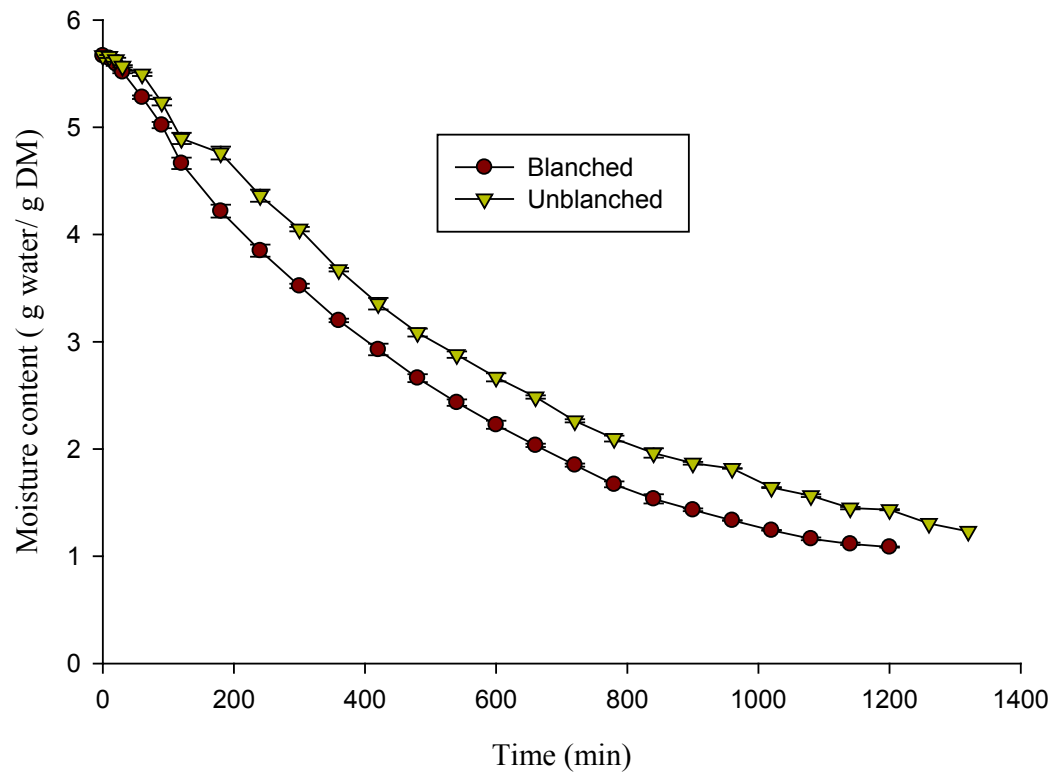

Figure 10c. Effect of blanching on the drying kinetics of $15 \mathrm{~mm}$-thick slices at $50^{\circ} \mathrm{C}$

The higher drying rates for blanched samples might be due the structural changes in the product during blanching, which causes the pore openings of the food material to become enlarged thus increasing the rate at which water is evaporated. Therefore, it can be concluded that, blanching aids in water loss from the internal regions of the potato slices to the surface during the drying process ${ }^{[26]}$. Furthermore, the effect of blanching seemed to increase with slice thickness as shown on Figures $10 \mathrm{~b}$ and $\mathrm{c}$. This might be due to the fact that for a smaller slice thickness, the moisture is closer to the surface and does not diffuse through a long distance such that the effect of blanching is not pronounced. For a greater slice thickness, the distance between the interior and the surface is longer; blanching causes pore openings and increases the permeability of cytoplasmic membranes facilitating water loss by diffusion through increased distances from the interior of the slices to the surface. Doymaz ${ }^{[27]}$ reported a similar pattern of increase in drying rate for pretreated samples of apricots.

At 60 and $70^{\circ} \mathrm{C}$ no significant differences were (Figure 10d) observed in the drying rates of the blanched and 
unbleached samples for all the sample thicknesses. This was attributed to the fact that at higher temperatures evaporation rates become higher thereby increasing the water flux to the surface such that the effect of thickness on the water diffusion rate becomes negligible. That is, as temperature increases, the effect of temperature on the diffusion rate of water becomes more pronounced compared to that of slice thickness ${ }^{[26]}$.

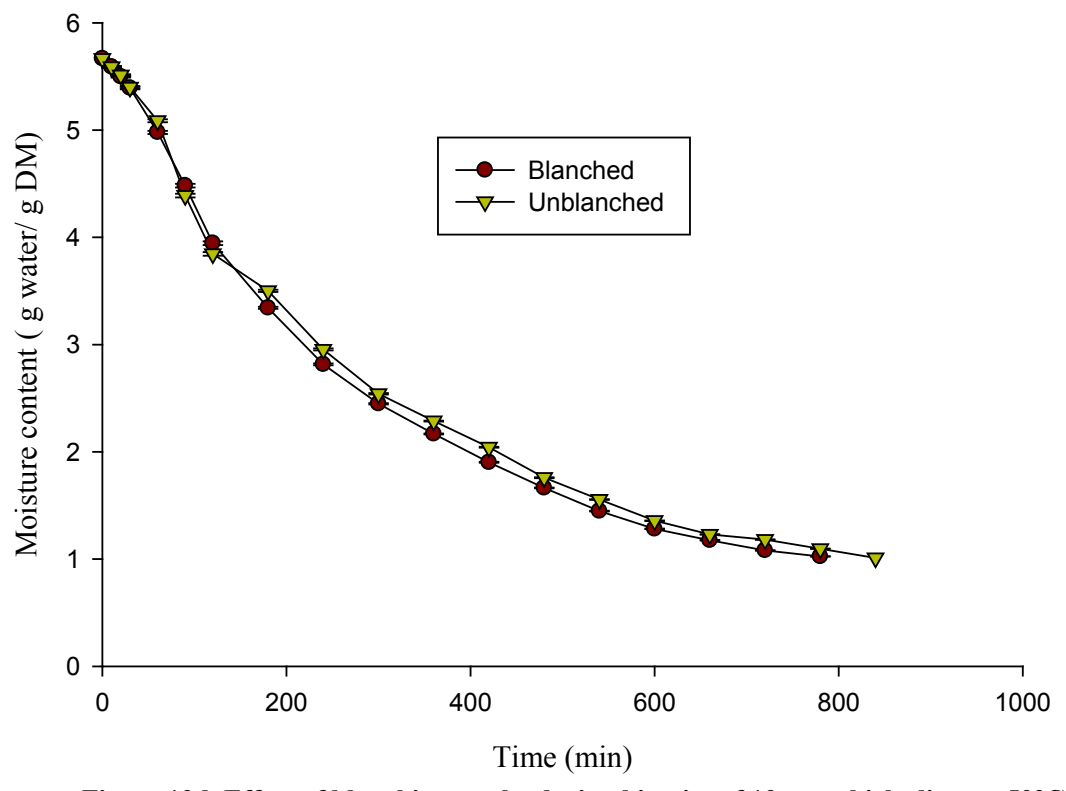

Figure 10d. Effect of blanching on the drying kinetics of $10 \mathrm{~mm}$-thick slices at $50^{\circ} \mathrm{C}$ (similar trends were observed for other slices thicknesses at 60 and $70^{\circ} \mathrm{C}$ )

\subsubsection{Evaluation of thin layer drying models}

Model constants and $\mathrm{R}^{2}$ values for the selected equations are presented on Table 7. The best model to describe the drying characteristics of the potato slices was selected on the basis of highest $\mathrm{R}^{2}$. The $\mathrm{R}^{2}$ values varied from 0.893 to 0.996 (5 mm); 0.967 to $0.998(10 \mathrm{~mm})$; and 0.971 to $0.995(15 \mathrm{~mm})$. Page model gave the highest value of $\mathrm{R}^{2}$ compared to the other two models and thus was found to be the most suitable to predict the hot air drying of potato slices at different drying temperatures. Similar findings have been reported by Goyal et al. ${ }^{[24]}$ on air drying of mango slices and Abano et al. ${ }^{[22]}$ (2011) on the drying characteristics of banana slices.

The suitability of Page model is further illustrated by the plot of experimental against the predicted moisture ratio for the $5 \mathrm{~mm}$ slice thickness at $50^{\circ} \mathrm{C}$ (Figure 11). 
Table 7. $\mathbf{R}^{2}$ and thin layer model constants

\begin{tabular}{|c|c|c|c|c|c|}
\hline \multicolumn{6}{|c|}{ Page model, $\mathrm{M}_{\mathrm{R}}=\exp \left(-\mathrm{kt}^{\mathrm{n}}\right)$} \\
\hline No. & Temp $\left({ }^{\circ} \mathrm{C}\right)$ & Slice thickness (mm) & $\overline{\mathrm{k}}$ & $\mathrm{N}$ & $\overline{\mathrm{R}^{2}}$ \\
\hline 1 & & 5 & 0.00064 & 1.342 & 0.992 \\
\hline 2 & 50 & 10 & 0.00048 & 1.310 & 0.991 \\
\hline 3 & & 15 & 0.00037 & 1.291 & 0.995 \\
\hline 4 & & 5 & 0.00012 & 1.261 & 0.996 \\
\hline 5 & 60 & 10 & 0.00067 & 1.297 & 0.992 \\
\hline 6 & & 15 & 0.00043 & 1.325 & 0.991 \\
\hline 7 & & 5 & 0.00011 & 1.388 & 0.994 \\
\hline 8 & 70 & 10 & 0.00083 & 1.338 & 0.998 \\
\hline 9 & & 15 & 0.00082 & 1.291 & 0.995 \\
\hline \multicolumn{6}{|c|}{ Henderson and Pabis model, $\mathrm{M}_{\mathrm{R}}=\mathrm{a} \exp (-\mathrm{kt})$} \\
\hline No. & Temp $\left({ }^{\circ} \mathrm{C}\right)$ & Slice thickness $(\mathrm{mm})$ & $\mathrm{a}$ & K & $\mathrm{R}^{2}$ \\
\hline 1 & & 5 & 0.590 & 0.007 & 0.893 \\
\hline 2 & 50 & 10 & 1.011 & 0.003 & 0.998 \\
\hline 3 & & 15 & 0.890 & 0.003 & 0.981 \\
\hline 4 & & 5 & 0.777 & 0.007 & 0.956 \\
\hline 5 & 60 & 10 & 0.852 & 0.004 & 0.967 \\
\hline 6 & & 15 & 0.904 & 0.003 & 0.990 \\
\hline 7 & & 5 & 0.595 & 0.013 & 0.950 \\
\hline 8 & 70 & 10 & 0.804 & 0.007 & 0.983 \\
\hline 9 & & 15 & 0.816 & 0.005 & 0.971 \\
\hline \multicolumn{6}{|c|}{ Newton model, $\mathrm{M}_{\mathrm{R}}=\exp (\mathrm{kt})$} \\
\hline No. & Temp $\left({ }^{\circ} \mathrm{C}\right)$ & Slice thickness $(\mathrm{mm})$ & $\mathrm{k}$ & & $\mathrm{R}^{2}$ \\
\hline 1 & & 5 & 0.007 & & 0.893 \\
\hline 2 & 50 & 10 & 0.003 & & 0.998 \\
\hline 3 & & 15 & 0.003 & & 0.981 \\
\hline 4 & & 5 & 0.007 & & 0.956 \\
\hline 5 & 60 & 10 & 0.004 & & 0.967 \\
\hline 6 & & 15 & 0.003 & & 0.990 \\
\hline 7 & & 5 & 0.013 & & 0.950 \\
\hline 8 & 70 & 10 & 0.007 & & 0.983 \\
\hline 9 & & 15 & 0.005 & & 0.971 \\
\hline
\end{tabular}

$\mathbf{k}, \mathbf{a}$ and $\mathbf{n}$ are model constants,

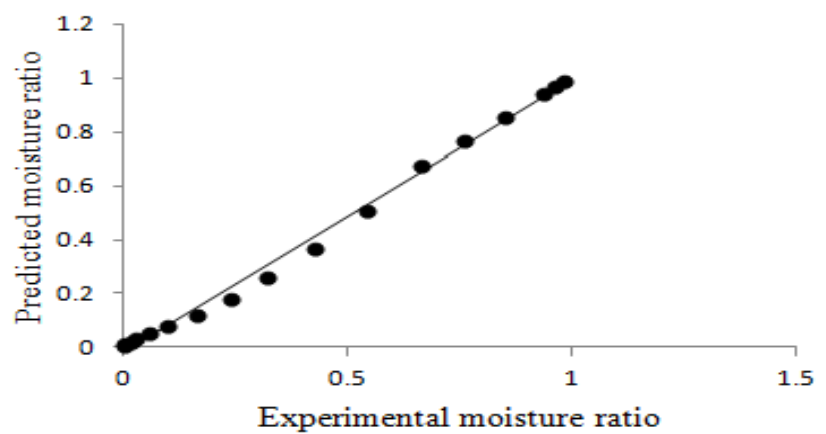

Figure 11. Experimental vs predicted moisture ratio at $50^{\circ} \mathrm{C}$ and thickness $5 \mathrm{~mm}$ for the page model

\section{Conclusion}

The optimum blanching conditions for potato slices were found to be: blanching temperature of $80^{\circ} \mathrm{C}$, for 3 minutes and at slice thickness of $10 \mathrm{~mm}$. Under these conditions Vitamin C loss was about 2.6\%. The blanching temperature, time and slice thickness were found to be the significant factors affecting vitamin $\mathrm{C}$ loss during the blanching process while temperature and slice thickness affected the drying process significantly. The three traditional phases of drying were observed with the blanched potato slices and this was attributed to free water added during the blanching process. The blanching pretreatment increased the drying rates for potato samples and reduce drying times by about $30 \%$. Page model was found to be the most suitable for describing the thin layer drying characteristic of potato slices. 


\section{Conflict of interest}

Authors declare no conflict of interest.

\section{References}

[1] FAO. FAO Production Statistics. Food and Agricultural Organisation. Rome 2009; Retrieved from www. faostat.fao. org.

[2] Bihnchang-Ngwa L, Mapiemfu-Lamare D, Fornkwa VY, et al. Six improved cameroonian potato varieties introduced in vitro through meristem culture. International Journal of Sciences: Basic and Applied Research. 2017; 36: $180-186$.

[3] FAOSTAT. Food and Agricultural Organization statistics 2019; Retrieved from http://www.fao.org/faostat/en/\#data/ QC, Accessed February 26, 2020.

[4] Yu S, Kazuyuki M, Yuuki M, et al. Breeding of a new potato variety 'Nagasaki Kogane' with high eating quality, high carotenoid content, and resistance to diseases and pests. Breeding Science. 2017; Available from: https://doi. org/10.1270/jsbbs. 16168 .

[5] Eaton TE, Azad AK, Kabir H, et al. Evaluation of six modern varieties of potatoes for yield, plant growth parameters and resistance to insects and diseases. Agricultural Sciences. 2017; 8: 1315-1326. Available from: 10.4236/ as.2017.811095

[6] Orsat V, Changrue V, Raghavan GS. Microwave Drying of Fruits and Vegetables. Stewart Post-Harvest Review. 2006; 6: 4-9.

[7] Brown CR. Antioxidants in potato. American Journal of Potato Research. 2005; 82: 163-172.

[8] Seyed-Hassan M, Ashtiani AS, Mahmood RG. Analyzing drying characteristics and modeling of thin layers of peppermint leaves under hot-air and infrared treatments. Information Processing in Agriculture. 2017; 4(2): $128-139$.

[9] Maté JI, Quartaert C, Meerdink G, et al. Effect of Blanching on Structural Quality of Dried Potato Slices. Journal of Agricultural and Food Chemistry. 1998; 46: 676-681. Available from: 10.1021/jf970671p

[10] Naderinezhad S, Etesami N, Poormalek Najafabady A, et al. Mathematical modeling of drying of potato slices in a forced convective dryer based on important parameters. Food Science Nutrition. 2015; 4: 110-8. Available from: $10.1002 /$ fsn 3.258

[11] Rifat J, Tahmeed A, Khalid G. Drying kinetics of potato using a self-designed cabinet dryer. Cogent Food Agriculture. 2015; 1: 1, 1036485, Available from: 10.1080/23311932.2015.1036485

[12] Kapadiya DC, Makavana JM, Kathiria MK. Effect of hot water blanching treatment on quality of dried potato slices. International Journal of Current Microbiologyy and Applied Sciences. 2018; 7: 2754-2764. Available from: 10.20546/ ijcmas.2018.707.322.

[13] Abdulla G, Gehan AE, Mahmoud ZS. Effect of pre-drying, blanching and citric acid treatments on the quality of fried sweet potato chips. American Journal of Food Technology. 2014; 9: 39-48.

[14] Artz W, Augustin J, Pettibone CA, Swanson BG. Vitamin C retention of potato fries blanched in water. Journal of Food Science. 2006; 48: 272-273. DOI: 10.1111/j.1365-2621.1983.tb14846.x

[15] Kapseu C, Nde Bup D, Tchiegang C, et al. Effect of particle size and drying temperature on drying rate and oil extracted yields of Buccholzia coriacea (MVAN) and Butyrospermum parkii ENGL. International Journal of Food Science and Technology. 2007; 42: 573-578.

[16] Nde Bup D, Abi Fon C, Kapseu C, et al. Indirect solar drying kinetics of sheanut (Vitellaria Paradoxa Gaertn.) kernels. International Journal of Postharvest Technology and Innovation. 2014; 4: (1): 1-22.

[17] Henderson SM, Pabis S. Grain drying theory I: temperature effect on drying coefficient. Journal of Agriculture and Engineering Research. 1969; 6 (3): 169-174.

[18] Page C. (1949) Factors Influencing the Maximum Rates of Air Drying of Shelled Corn in Thin Layers, Unpublished MS thesis, Purdue University, Lafayette. In: in Kashaninejad, M., Mortazavi A, Safekordi A, Tabil LG. Thin-layer drying characteristics and modeling of pistachio nuts. Journal of Food Engineering. 2007; 78: 98-108.

[19] Nde Bup D, Abi Fon C, Tenin D, et al. Optimisation of the Cooking Process of Sheanut Kernels (Vitellaria paradoxa Gaertn.) Using the Doehlert Experimental Design. Food and Bioprocess Technology. 2012; 5 (1): Available from: 108-117 DOI: $10.1007 / \mathrm{s} 11947-009-0274-z$.

[20] Nde Bup D, Boldor D, Astete C. Optimization of microwave assisted extraction parameters of neem (Azadirachta indica A. Juss) oil using the Doehlert's experimental design. Industrial Crops and Products. 2015; 65: 233-240.

[21] Severini C, Giuliani R, De Filippis A, et al. Influence of different blanching methods on colour, ascorbic acid and phenolics content of broccoli. Journal of Food Science and Technology. 2016; 53(1): 501-510. DOI 10.1007/s13197015-1878-0 
[22] Abano EE, Ma H, Qu W. Influence of air temperature on the drying kinetics and quality of Tomato slices. Journal of Food Processing and Technology. 2011; 2: 1-9. Available from: 10.4172/2157-7110.1000123.

[23] Seyed-Hassan M, Barbara S, Abozar N. Effects of hot-air and hybrid hot air-microwave drying on drying kinetics and textural quality of nectarine slices. Heat and Mass Transfer. 2018; 54: 915-927.

[24] Goyal RK, Kingsly ARP, Manikantan MR, et al. Mathematical modeling of thin layer drying kinetics of plum in a tunnel dryer. Journal of Food Engineering. 2006; 79: 176-80.

[25] Waananen KM. Analysis of Mass Transfer Mechanisms during Drying of Extruded Pasta, [PhD dissertation], Purdue University; 1989.

[26] Blasco M, García-Pérez JV, Bon J, et al. Effect of blanching and air flow rate on turmeric drying. Food Science and Technology International. 2006; 12: 315-323.

[27] Doymaz I. Effect of pre-treatments using potassium metabisulphite and alkaline ethyl- oleate on the drying kinetics of apricots. Biosystem Engineering. 2009; 89: 281-287. 